\title{
Internal Control Effectiveness and Stock Price Crash Risk: Evidence from China
}

\author{
Fusheng Wang*, Jieqiong Hu \\ School of Management, Harbin Institute of Technology, Harbin, China \\ Email address: \\ wangfusheng_hit@sina.com (Fusheng Wang), qiongeasy@sina.com (Jieqiong Hu) \\ ${ }^{*}$ Corresponding author
}

\section{To cite this article:}

Fusheng Wang, Jieqiong Hu. Internal Control Effectiveness and Stock Price Crash Risk: Evidence from China. American Journal of Theoretical and Applied Business. Vol. 6, No. 4, 2020, pp. 66-71. doi: 10.11648/j.ajtab.20200604.13

Received: October 31, 2020; Accepted: November 11, 2020; Published: November 19, 2020

\begin{abstract}
Stock price crash is the extreme negative values of price distribution which can make investors suffer from huge losses and harm the stability of security market. Because of the heavy consequences, how to avoid stock price crash is a topic of significant importance. According to the "bad news hoarding" theory, transparency is a key determinant to restrain stock price crash risk. This is because transparent firms can fairly and comprehensively transfer information to investors, thus reduce the information asymmetry between the two parties. Internal control is an intergraded institutional arrangement and aims at improving reporting quality. In theory, internal control plays a role in impacting transparency and further affects stock price crash risk. Selecting companies listed on China's main board from 2008 to 2019 and conducting mediating effect tests, this paper explores the mechanism on how internal control effectiveness influences stock price crash risk. Findings show that: (1) internal control effectiveness is negatively correlated to stock price crash risk; (2) internal control effectiveness is positively correlated to transparency; (3) transparency is negatively related to stock price crash risk; and (4) internal control effectiveness has a partial mediating effect on the relationship between internal control effectiveness and stock price crash risk. The findings indicate that effective internal control can decrease stock price crash risk via enhancing transparency. This paper extends extant literature by investigating the mechanism on how internal control effectiveness affects stock price crash in the emerging market of China.
\end{abstract}

Keywords: Internal Control Effectiveness, Stock Price Crash Risk, Transparency

\section{Introduction}

Stock price crash refers to the phenomenon that stock price drops sharply in a short time, which is pervasive in Chinese security market. Investors would suffer from wealth vanishing during the crash, so how to avoid stock price crash is a topic of importance.

Jin and Myers posit the "bad news hoarding" theory to explain why stock price crash occurs [1]. They state that managers would select particular information to disclose and hide the bad news. As bad news accumulates to a threshold which is the maximum the firm can burden, managers give up to continue hoarding bad news, then bad news will release to the market intensively. Investors will react to the bad news and sell off the stock shares to avoid more loss, and stock price experiences a sudden drop. "Bad news hoarding" theory also points out that transparency is a key determinant of stock price crash risk. In a transparent firm, information asymmetry between investors and managers is relatively weak, and bad news hoarding is less likely to occur.

Internal control is a general process embedded in a firm's inside governance and aims at assuring reporting quality, compliance to regulations and operating efficiency. This paper investigates the mechanism of stock price crash formation from the perspective of internal control, and finds that effective internal control can reduce stock price crash risk through improving transparency. This paper explores the mediating role of transparency in the relationship between internal control effectiveness and stock price crash risk, contributing to the literature of internal control consequences and literature of stock price crash determinants by providing evidence from the transition economy of China. 


\section{Literature Review}

Our paper is related to two streams of literature: the consequences of internal control and the determinants of stock price crash risk.

\subsection{Consequences of Internal Control}

As internal control objectives include the reliability of financial reporting, the compliance of applicable regulations and laws and the improvement of operating efficiency, previous studies try to provide evidence on whether internal control can achieve the objectives.

In terms of the reporting objective, Doyle et al. find that ineffective internal control is correlated to lower earnings quality, and the relationship mainly exists among the company-level internal control deficiencies rather than account-level internal control deficiencies [2]. Chan et al. hold the same opinion [3]. Ashbaugh-Skaife et al. explore how ineffective internal control affects the quality and magnitude of earnings quality and conjecture that there are two categories of misstatements, namely intentional and unintentional errors [4]. Ashbaugh-Skaife et al. also state that companies with internal control deficiencies report more earnings noise, while earnings quality experiences an improvement after the deficiencies remediation [4]. Goh and Li pay attention to the effect of internal control on conditional conservatism and find management are prone to make more conservative decisions when the internal control is effective [5].

From the perspective of compliance objective, Rice et al. point out that the lacking of regulatory monitoring restrains the positive effects of internal controls [6]. Rice et al. find companies who fail to report existed internal control weaknesses do not face sanctions and argue the current supervision from regulators is not stringent enough [6].

Extant studies also explore the consequences of internal control in the aspect of operating objective. Feng et al. find that ineffective internal control is related to lower inventory turnover and more inventory impairment. However, after rectifying internal control deficiencies, inventory turnover rate enhances with income and operating cash flow increasing [7]. D'Mello et al. find internal control can affect the internal capital allocation. To be more specific, ineffective internal control is correlated to lower internal capital transferring efficacy [8].

Overall, previous studies mainly focus on the effects of internal control on reporting quality and operating performance, but scant evidence is provided from the perspective of stock price crash.

\subsection{Determinants of Stock Price Crash Risk}

Existed literature explores the factors that may affect stock price crash risk and obtains abundant results.

Chen et al. find the earnings smoothing exacerbates stock price crash risk [9]. Kubic et al. investigate whether proximity to SEC affects stock price crash risk and find that companies geographically closer to SEC are exposed in lower price crash threatening [10]. $\mathrm{Xu}$ et al. explore the relationship between analyst herding and stock price crash risk, and find higher stock price crash risk is related to stronger analyst herding [11] Liang et al. study the relationship between ultimate ownership and stock price crash risk. They use the split share structure reform in China to design a quasi-natural experiment and observe the average crash risk of China's market experiences a decline after the reform and the risk reduction is more pounced among private sectors compared to state-owned firms [12].

In general, previous studies provide tremendous evidence on how a particular factor can affect stock price crash risk, but still lack the evidence from internal control.

\section{Theoretical Analysis}

It is widely accepted that transparency is the key determinant of stock price crash risk. Jin and Myers establish an information structure model to express the role of transparency on affecting stock price crash risk, and use cross-country data to provide evidence [1]. Afterwards, Hutton et al. employ firm-level data to confirm the assumption in a more microscopic way. In theory, internal control can help enhancing transparency, and thus reduce stock price crash risk [13].

\subsection{Internal Control and Transparency}

Cost of obtaining information is a feature of the incomplete market. During the information disclosure procedure, managers are prone to select and hide particular information regarding opportunistic incentive [14], which obviously harm information availability and thus deteriorate transparency.

Internal control is a systematic process that covers all aspects of internal governance. Effective internal controls can curtail international and unintentional errors of financial reporting [4], and thus helps investors to receive high-quality information. The main reason to opaqueness is that managers take advantage of information source to reassign and reorganize which part of information will transfer to outsiders. In other words, opaqueness makes managers' manipulation more convenient. Hutton et al. find that companies with more earnings management tend to restate more frequently, indicating that companies with more manipulation tend to expose in a lower transparent environment [13]. Ashbaugh-Skaife et al. find that companies with ineffective internal controls tend to manipulate earnings more often, while earnings quality enhances after internal control deficiencies remediation, implying strengthening internal control helps improving transparency [4]. In general, higher internal control effectiveness is correlated to higher transparency.

\subsection{Internal Control, Transparency and Stock Price Crash Risk}

Opaqueness is regarded as a key reason to why Chinese listed companies always face high stock price crash risk [15]. Internal control aims at providing reasonable insurance to reliable corporate reporting, which significantly helps preventing mangers from hiding and hoarding bad news and thus reduces stock price crash risk. 
Incomplete contract theory states that complete contracts cannot exist regarding incomplete ration, incomplete information and incomplete transaction recognition. Opaqueness is driven by incomplete contracts. Insiders can acquire all the firm-specific information, so they are able to seize more residual control rights and more private benefits. Internal control, as a compensatory mechanism of incomplete contracts, can reassign and rectify the control rights distribution among all the corporate operating procedures and thus restrain managers' opportunistic behavior. In fact, internal control is a general process that requiring different departments to hold mutual supervision to each other and finally achieves the control objectives including trustable information disclosure. Effective internal control would aggravate the risk which managers burden for dishonest behavior; hence increases managers' cost on hiding bad news. If internal control exerts enough pressure on managers, managers would give up hiding bad news. Meanwhile, the information environment tends to be transparent and investors can receive relatively fair and comprehensive information which helps them to evaluate firm value more precisely. Therefore, stock price bubble is less likely to last and stock price crash risk is restrained. In sum, transparency is the key channel through which internal control can affect stock price crash risk. Hence we posit the hypothesis.

H1: Effective internal control can decrease stock price crash risk via improving transparency.

\section{Methodology}

\subsection{Samples}

We select companies listed on mainboard of China from 2008 to 2019 as the initial sample and (1) delete samples with dealing weeks less than 30 weeks a year based on Jin and Myers [1]; (2) delete samples with missing data; and (3) delete samples within financial and insurance industry. Finally, we obtain a sample of 8228 observations. Internal control data are collected from DIB dataset and other data are collected from CSMAR dataset. All continuous variables are winsoried by $1 \%$ and $99 \%$ quantiles.

\subsection{Modelling}

In order to test H1, we follow Baron et al. (1986) [16] to investigate whether transparency plays a mediating role in the relationship of internal control effectiveness and stock price crash risk. The whole mediating effect test process can be divided into four steps. Step 1, examine if internal control effectiveness can significantly affect stock price crash risk. If yes, then step 2 is conducted. Step 2, examine if internal control effectiveness can significantly affect transparency. If yes, then step 3 is conducted. Step 3, examine if transparency can significantly affect stock price crash risk. If yes, then step 4 is conducted. Step 4, examine if transparency mediates the relationship of internal control effectiveness and stock price crash risk. Next, we illustrate the models involved in each step.
We build the following model for step 1 .

$$
\text { Crash }_{t+1}=\alpha_{0}+\alpha_{1} I_{C E}+\alpha \text { Controls }_{t}+F E+\varepsilon
$$

where Crash represents stock price crash risk; ICE represents internal control effectiveness; Controls represents a variety of control variables; $F E$ represents the industry and year fixed effects; $\varepsilon$ represents the error term. If $\alpha_{l}$ is significant, then we move to step 2 using the following model.

$$
\operatorname{Tran}_{t}=\beta_{0}+\beta_{1} \text { ICE }_{t}+\beta \text { Controls }_{t}+F E+\varepsilon
$$

where Tran represents transparency and other variables are the same as they are in model (1). If $\beta_{l}$ is significant, then we move to step 3 using the following model.

$$
\text { Crash }_{t+1}=\gamma_{0}+\gamma_{1} \text { Tran }_{t}+\gamma \text { Control }_{t}+F E+\varepsilon
$$

where all variables definition are the same as they are in model (1) and (2). If $\gamma_{1}$ is significant, then we move to step 4 using the following model.

$$
\text { Crash }_{t+1}=\lambda_{0}+\lambda_{1} \text { ICE }_{t}++\lambda_{2} \text { Tran }_{t}+\lambda \text { Controls }_{t}+F E+\varepsilon
$$

where all variables definition are the same as they are in model (1), (2) and (3). An insignificant $\lambda_{I}$ indicates there is a full mediating effect while a significant $\lambda_{l}$ indicates there is a partial mediating effect.

\subsection{Variables Definition}

\subsubsection{Measuring Stock Price Crash Risk}

Following Kim et al. [17], we use two proxies to measure stock price crash risk. The first proxy is negative conditional return skewness (Ncskew) and the second proxy is down-to-up volatility ( $\mathrm{Duvol}$ ). We calculate the two measures based on the method provided by Chen et al. [18].

First, we build the following model to estimate firm-specific weekly return.

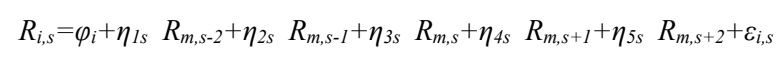

where $R_{i, s}$ is the return of stock $i$ in week $s ; R_{m, s}$ is the market return in week $s ; R_{m, s-2}, R_{m, s-1}, R_{m, s+1}$ and $R_{m, s+2}$ are the lag and lead terms of $R_{m, s}$. Regress model (5) each firm each year and we get the residual $\varepsilon_{i, s}$, who captures the part of firm stock return cannot explained by market return. Create $W_{i, s}=\ln$ $\left(1+\varepsilon_{i, s}\right)$ to capture the firm-specific weekly return. Then calculate Ncskew by estimating the following model.

$$
\text { Ncskew }_{i, t}=\left[-n(n-1)^{3 / 2} \sum W_{i, s}^{3}\right] /\left[(n-1)(n-2)\left(\sum W_{i, s}{ }^{2}\right)^{3 / 2}\right]
$$

where $n$ represents the number of dealing weeks of firm $i$ among year $t$.

Next we calculate Duvol by estimating the following model.

$$
\text { Duvol=ln }\left[\left(n_{u}-1\right) \sum_{d o w n} W_{i, s}{ }^{2} /\left(n_{d}-1\right) \sum_{u p} W_{i, s}{ }^{2}\right]
$$

where $n_{u}$ represents the number of "up" weeks and $n_{d}$ represents the number of "down" weeks of firm $i$ among year $t$. We divide all the dealing weeks into two groups by the benchmark of average return. Weeks with return higher than 
average are regarded as "up" weeks, and otherwise "down" weeks. The larger Ncskew and Duvol, the higher stock price crash risk.

\subsubsection{Measuring Transparency}

Following Hutton et al. [13], we use discretional accruals calculated by modified Jones model to measure transparency. We estimate the following model by year and by industry.

$$
T A=\delta_{0}+\delta_{I}(\Delta R E V-\triangle R E C)+\delta_{2} P P E+\varepsilon
$$

where $T A$ is the total accruals, i.e. net profit minus operating cash flow; $\triangle R E V$ is the incremental sales; $\triangle R E C$ is the incremental accounts receivable; $P P E$ is property, plant and equipment. All terms involved in the model are scaled by lagged total assets and we get the residuals which captures the abnormal accruals. We take the absolute value of the residuals to measure transparency based on Hutton et al. [13], and use Tran to denote. The higher Tran, the lower transparency.

\subsubsection{Measuring Internal Control Effectiveness}

We collect DIB internal control index from DIB dataset. DIB internal control index is an integrated index to measure internal control effectiveness and is widely used in China-based studies. DIB internal control index gets a range of 0 to 1000 , and higher score indicates better internal control effectiveness. We define $I C E=\ln$ (DIB internal control index $+1)$ to measure internal control effectiveness. The higher $I C E$, the stronger internal control effectiveness.

\subsubsection{Control Variables}

Following Hutton et al. [13], we set a variety of control variables including Ncskew, DTurn, Sigma, Ret, Size, BM, $L E V, R O A$. All variables definition is listed in Table 1.

Table 1. Variable definition.

\begin{tabular}{ll}
\hline Variable & Definition \\
\hline Ncskew & Negative coefficient of skewness of firm-specific return \\
Duvol & Down-to-up volatility ratio of firm-specific weekly return \\
Tran & Absolute value of discretional accruals \\
ICE & Ln (DIB internal control index +1$)$ \\
DTurn & Excess turnover rate \\
Sigma & Standard deviation of firm-specific weekly return \\
Ret & Yearly average firm-specific weekly return \\
Size & Ln (total assets) \\
BM & Market-to-book ration \\
LEV & Liability/assets \\
ROA & Income/assets \\
\hline
\end{tabular}

\section{Results}

\subsection{Descriptive Statistics}

Table 2 displays the descriptive statistics of the main variables. The mean of $N$ cskew $w_{t+1}$ and Duvol $_{t+1}$ are -0.401 and -0.323 , respectively, which are consistent with the existed studies[12]. The mean, minim and maximum of $\operatorname{Tran}_{t}$ are $0.076,0.001$ and 0.613 , respectively, indicating there are significant difference of transparency among firms. The mean, minim and maximum of $I C E_{t}$ are $6.340,0$ and 6.903, respectively, implying internal control effectiveness varies among particular companies.

Table 2. Descriptive Statistics.

\begin{tabular}{lllllll}
\hline Variable & No. & Mean & P50 & Min & Max & Sd \\
\hline Ncskew $_{t+1}$ & 8228 & -0.401 & -0.434 & -5.504 & 4.789 & 1.028 \\
Duvol $_{t+1}$ & 8228 & -0.323 & -0.330 & -5.767 & 5.674 & 0.893 \\
Tran $_{t}$ & 8228 & 0.076 & 0.047 & 0.001 & 0.613 & 0.087 \\
ICE $_{t}$ & 8228 & 6.340 & 6.534 & 0 & 6.903 & 1.103 \\
Ncskew $_{t}$ & 8228 & -0.265 & -0.228 & -3.165 & 2.435 & 0.967 \\
DTurn $_{t}$ & 8228 & -2.132 & -2.543 & -64.15 & 67.16 & 24.76 \\
Sigma $_{t}$ & 8228 & 0.056 & 0.045 & 0.021 & 0.134 & 0.020 \\
Ret $_{t}$ & 8228 & -0.003 & -0.003 & -0.021 & 0.025 & 0.007 \\
Size $_{t}$ & 8228 & 22.67 & 22.45 & 19.03 & 27.89 & 1.254 \\
BM $_{t}$ & 8228 & 0.065 & 0.651 & 0.108 & 1.106 & 0.154 \\
LEV $_{t}$ & 8228 & 0.564 & 0.545 & 0.079 & 1.129 & 0.187 \\
ROA $_{t}$ & 8228 & 0.034 & 0.031 & -0.216 & 0.197 & 0.056 \\
\hline
\end{tabular}

\subsection{Grouped Test}

Before moving on to the regression test, we conduct grouped test first to provide some preliminary results on whether transparency can affect the correlation between internal control effectiveness and stock price crash risk. We divide the sample into two groups according to different transparency levels. We classify the companies with Tran higher than the median as the "low transparency group", and classify the companies with $\operatorname{Tran}_{t}$ lower than the median as the "high transparency group". Model (1) is estimated using the two sub-samples respectively and Table 3 displays the results. Column (1) and (2) show that the coefficients of $I C E_{t}$ are always significantly negative no matter measuring stock price crash by $N_{c s k e w_{t+1}}$ or Duvol $l_{t+1}$, meaning that there is a negative correlation between internal control effectiveness and stock price crash risk within the low transparency group. Column (3) and (4) show that the coefficients of $I C E_{t}$ are not significant, indicating the relationship between internal control effectiveness and stock price crash risk is not statistically existed within the high transparency group. In sum, transparency can affect the relationship between internal control effectiveness and stock price crash risk.

\subsection{Regression Results}

Table 4 presents the estimation results of Model (1), (2), (3) and (4) using $N$ cskew $_{t+1}$ to measure stock price crash risk while Table 5 presents the results using Duvol $_{t+1}$ to measure stock price crash risk.

Table 4 Column (1) shows that the coefficient of $I C E_{t}$ is negative and significant at $1 \%$ level, indicating that strong internal control effectiveness can reduce stock price crash risk. Table 4 Column (2) shows that effective internal control can enhance transparency. Table 4 Column (3) shows better transparency leads to lower stock price crash risk. Table 4 Column (4) shows that both coefficients of $I C E_{t}$ and $\operatorname{Tran}_{t}$ are significant, implying that transparency plays a partial mediating role in the relationship between internal control effectiveness and stock price crash risk. 
Table 3. Grouped test.

\begin{tabular}{|c|c|c|c|c|}
\hline & \multicolumn{2}{|c|}{ Low transparency group } & \multicolumn{2}{|c|}{ High transparency group } \\
\hline & (1) Ncskew $w_{t+1}$ & (2) $D u v o l_{t+1}$ & (3) Ncskew $w_{t+1}$ & (4) $D u v^{\prime} l_{t+1}$ \\
\hline$I C E_{t}$ & $\begin{array}{l}-0.073 * * * \\
(-3.789)\end{array}$ & $\begin{array}{l}-0.048 * * * \\
(-2.967)\end{array}$ & $\begin{array}{l}-0.011 \\
(-0.644)\end{array}$ & $\begin{array}{l}-0.004 \\
(-0.324)\end{array}$ \\
\hline Ncskew $_{t}$ & $\begin{array}{l}0.046 \\
(-1.623)\end{array}$ & $\begin{array}{l}0.035 \\
(-1.443)\end{array}$ & $\begin{array}{l}0.050^{*} \\
(-2.516)\end{array}$ & $\begin{array}{l}0.037 * * \\
(-2.261)\end{array}$ \\
\hline DTurn $_{t}$ & $\begin{array}{l}-0.029 * * \\
(-2.324)\end{array}$ & $\begin{array}{l}-0.003 * * * \\
(-3.166)\end{array}$ & $\begin{array}{l}-0.001 \\
(-1.163)\end{array}$ & $\begin{array}{l}-0.001 * \\
(-1.956)\end{array}$ \\
\hline Sigma $_{t}$ & $\begin{array}{l}2.757^{*} \\
(-1.779)\end{array}$ & $\begin{array}{l}1.915 \\
(-1.545)\end{array}$ & $\begin{array}{l}0.435 \\
(-0.386)\end{array}$ & $\begin{array}{l}1.145 \\
(-1.266)\end{array}$ \\
\hline $\operatorname{Ret}_{t}$ & $\begin{array}{l}19.312 * * * \\
(-5.269)\end{array}$ & $\begin{array}{l}16.773 * * * \\
(-5.725)\end{array}$ & $\begin{array}{l}19.763^{* * *} \\
(-7.349)\end{array}$ & $\begin{array}{l}15.882 * * * \\
(-7.253)\end{array}$ \\
\hline Size $_{t}$ & $\begin{array}{l}0.192 * * * \\
(-8.386)\end{array}$ & $\begin{array}{l}0.178^{* * * *} \\
(-9.189)\end{array}$ & $\begin{array}{l}0.146^{* * * *} \\
(-7.512)\end{array}$ & $\begin{array}{l}0.109 * * * \\
(-6.919)\end{array}$ \\
\hline$B M_{t}$ & $\begin{array}{l}-0.885 * * * \\
(-6.882)\end{array}$ & $\begin{array}{l}-0.824 * * * \\
(-7.862)\end{array}$ & $\begin{array}{l}-0.924 * * * \\
(-9.054)\end{array}$ & $\begin{array}{l}-0.712 * * * \\
(-8.881)\end{array}$ \\
\hline$L E V_{t}$ & $\begin{array}{l}-0.183 \\
(-1.512)\end{array}$ & $\begin{array}{l}-0.189^{*} \\
(-1.950)\end{array}$ & $\begin{array}{l}-0.119 \\
(-1.272)\end{array}$ & $\begin{array}{l}-0.117 \\
(-1.615)\end{array}$ \\
\hline$R O A_{t}$ & $\begin{array}{l}-0.281 \\
(-0.876)\end{array}$ & $\begin{array}{l}-0.513 * \\
(-1.910)\end{array}$ & $\begin{array}{l}-1.134 * * * \\
(-2.978)\end{array}$ & $\begin{array}{l}-0.858 * * * \\
(-2.646)\end{array}$ \\
\hline $\begin{array}{l}\text { Obs. } \\
\text { Adj-R }\end{array}$ & $\begin{array}{l}2677 \\
0.081\end{array}$ & $\begin{array}{l}2677 \\
0.087\end{array}$ & $\begin{array}{l}5551 \\
0.078\end{array}$ & $\begin{array}{l}5551 \\
0.079\end{array}$ \\
\hline
\end{tabular}

Note: $* * *$ and $* * *$ indicate statistical significance at $10 \%, 5 \%$ and $1 \%$ level, respectively. T-statistics are shown in parentheses.

Table 4. Regression of internal control effectiveness, transparency and stock price crash risk (I)

\begin{tabular}{|c|c|c|c|c|}
\hline & (1) Ncskew tr+1 & (2) $\operatorname{Tran}_{t}$ & (3) Ncskew $t_{t+1}$ & (4) Ncskew ${ }_{t+1}$ \\
\hline & Model (1) & Model (2) & Model (3) & Model (4) \\
\hline \multirow[t]{2}{*}{$I C E_{t}$} & $-0.035 * * *$ & $-0.002 * * *$ & & $-0.034 * * *$ \\
\hline & $(-2.788)$ & $(-2.939)$ & & $(-2.728)$ \\
\hline \multirow[t]{2}{*}{$\operatorname{Tran}_{t}$} & & & $0.314 * * *$ & $0.298 * *$ \\
\hline & & & $(2.61)$ & $(2.496)$ \\
\hline \multirow[t]{2}{*}{ Ncskew ${ }_{t}$} & $0.054 * * *$ & $0.004 * *$ & $0.057 * * *$ & $0.055 * * *$ \\
\hline & $(3.201)$ & (1.995) & $(3.253)$ & $(3.154)$ \\
\hline \multirow[t]{2}{*}{ DTurn $_{t}$} & $-0.003 * *$ & $-0.001 * * *$ & $-0.002 * *$ & $-0.002 * *$ \\
\hline & $(-2.258)$ & $(-4.686)$ & $(-2.146)$ & $(-2.119)$ \\
\hline \multirow[t]{2}{*}{ Sigma $_{t}$} & 1.432 & $0.512 * * *$ & 1.397 & 1.279 \\
\hline & $(1.543)$ & $(5.361)$ & $(1.485)$ & (1.369) \\
\hline \multirow[t]{2}{*}{$\operatorname{Ret}_{t}$} & $19.975 * * *$ & 0.231 & $19.807 * * *$ & $19.898 * * *$ \\
\hline & $(9.397)$ & (1.119) & $(9.296)$ & $(9.355)$ \\
\hline \multirow[t]{2}{*}{ Size $_{t}$} & $0.159 * * *$ & -0.004 & $0.157 * * *$ & $0.159 * * *$ \\
\hline & $(10.377)$ & $(-1.597)$ & (10.288) & $(10.451)$ \\
\hline \multirow[t]{2}{*}{$B M_{t}$} & $-0.884 * * *$ & $-0.019 * *$ & $-0.893 * * *$ & $-0.879 * * *$ \\
\hline & $(-11.283)$ & $(-1.986)$ & $(-11.437)$ & $(-11.236)$ \\
\hline \multirow[t]{2}{*}{$L E V_{t}$} & $-0.129 *$ & $0.031 * * *$ & $-0.123 *$ & $-0.138 *$ \\
\hline & $(-1.759)$ & $(3.061)$ & $(-1.679)$ & $(-1.882)$ \\
\hline \multirow[t]{2}{*}{$R O A_{t}$} & $-0.688 * * *$ & -0.002 & $-0.848 * * *$ & $-0.689 * * *$ \\
\hline & $(-2.867)$ & $(-0.087)$ & $(-3.554)$ & $(-2.863)$ \\
\hline Obs. & 8228 & 8228 & 8228 & 8228 \\
\hline $\operatorname{Adj}-R^{2}$ & 0.075 & 0.086 & 0.078 & 0.076 \\
\hline
\end{tabular}

Note: $* * *$ and $* * *$ indicate statistical significance at $10 \%, 5 \%$ and $1 \%$ level, respectively. T-statistics are shown in parentheses.

Using Duvol $_{t+1}$ to measure stock price crash risk, Table 5 presents the regression results of Model (1) to Model (4). From the table, we can know that (1) internal control effectiveness is negatively related to stock price crash risk; (2) internal control effectiveness is positively related to transparency; (3) transparency is negatively related to stock price crash risk; and (4) transparency has a partial mediating effect on the relationship between internal control effectiveness and stock price crash risk.
In sum, transparency is the key channel through which internal control effectiveness affects stock price crash risk.

Table 5. Regression of internal control effectiveness, transparency and stock price crash risk (II)

\begin{tabular}{|c|c|c|c|c|}
\hline & (1) Duvol $_{t+1}$ & (2) $\operatorname{Tran}_{t}$ & (3) Duvol $_{t+1}$ & (4) Duvol t+1 $_{t}$ \\
\hline & Model (1) & Model (2) & Model (3) & Model (4) \\
\hline$I C E_{t}$ & $\begin{array}{l}-0.023 * * \\
(-2.131)\end{array}$ & $\begin{array}{l}-0.003 * * * \\
(-2.939)\end{array}$ & & $\begin{array}{l}-0.021 * * \\
(-2.048)\end{array}$ \\
\hline $\operatorname{Tran}_{t}$ & & & $\begin{array}{l}0.245 * * * \\
(2.587)\end{array}$ & $\begin{array}{l}0.237 * * \\
(2.507)\end{array}$ \\
\hline Ncskew $_{t}$ & $\begin{array}{l}0.038 * * * \\
(2.916)\end{array}$ & $\begin{array}{l}0.003 * * \\
(1.995)\end{array}$ & $\begin{array}{l}0.038 * * * \\
(2.936)\end{array}$ & $\begin{array}{l}0.039 * * * \\
(2.862)\end{array}$ \\
\hline DTurn $_{t}$ & $\begin{array}{l}-0.002 * * * \\
(-3.650)\end{array}$ & $\begin{array}{l}-0.001 * * * \\
(-4.686)\end{array}$ & $\begin{array}{l}-0.002 * * * \\
(-3.334)\end{array}$ & $\begin{array}{l}-0.002 * * * \\
(-3.313)\end{array}$ \\
\hline $\operatorname{Sigma}_{t}$ & $\begin{array}{l}1.567 * * \\
(2.101)\end{array}$ & $\begin{array}{l}0.512 * * * \\
(5.361)\end{array}$ & $\begin{array}{l}1.507 * * \\
(2.027)\end{array}$ & $\begin{array}{l}1.437 * \\
(1.932)\end{array}$ \\
\hline $\operatorname{Ret}_{t}$ & $\begin{array}{l}16.437 * * * \\
(9.675)\end{array}$ & $\begin{array}{l}0.231 \\
(1.119)\end{array}$ & $\begin{array}{l}16.328 * * * \\
(9.598)\end{array}$ & $\begin{array}{l}16.383 * * * \\
(9.637)\end{array}$ \\
\hline Size $_{t}$ & $\begin{array}{l}0.132 * * * \\
(10.474)\end{array}$ & $\begin{array}{l}-0.004 \\
(-1.599)\end{array}$ & $\begin{array}{l}0.131 * * * \\
(10.451)\end{array}$ & $\begin{array}{l}0.132 * * * \\
(10.551)\end{array}$ \\
\hline$B M_{t}$ & $\begin{array}{l}-0.731 * * * \\
(-11.688)\end{array}$ & $\begin{array}{l}-0.019 * * \\
(-1.977)\end{array}$ & $\begin{array}{l}-0.735^{* * *} \\
(-11.767)\end{array}$ & $\begin{array}{l}-0.727 * * * \\
(-11.642)\end{array}$ \\
\hline$L E V_{t}$ & $\begin{array}{l}-0.134 * * \\
(-2.288)\end{array}$ & $\begin{array}{l}0.031 * * * \\
(3.052)\end{array}$ & $\begin{array}{l}-0.133 * * \\
(-2.254)\end{array}$ & $\begin{array}{l}-0.141 * * \\
(-2.405)\end{array}$ \\
\hline$R O A_{t}$ & $\begin{array}{l}-0.678 * * * \\
(-3.315)\end{array}$ & $\begin{array}{l}-0.003 \\
(-0.078)\end{array}$ & $\begin{array}{l}-0.772 * * * \\
(-3.785)\end{array}$ & $\begin{array}{l}-0.678 * * * \\
(-3.313)\end{array}$ \\
\hline Obs. & 8228 & 8227 & 8228 & 8228 \\
\hline $\operatorname{Adj}-R^{2}$ & 0.077 & 0.085 & 0.078 & 0.077 \\
\hline
\end{tabular}

Note: $* * *$ and $* * *$ indicate statistical significance at $10 \%, 5 \%$ and $1 \%$ level, respectively. T-statistics are shown in parentheses.

\section{Conclusion}

This paper examines the mechanism on how internal control effectiveness can affect stock price crash risk. Findings show that: (1) effective internal control can restrain stock price crash risk; (2) internal control effectiveness is positively related to transparency; (3) companies with transparent environment are more prone to expose in low stock price crash risk; and (4) transparency has a partial mediating effect on the relationship between internal control effectiveness and stock price crash risk.

The findings of this paper have theoretical and practical implications. In the theoretical aspect, taking transparency into consideration can help deeply understand the mechanism of how internal control effectiveness affects stock price crash risk. Stock price always fluctuates around its inside value. As an extreme distribution of price, stock price crash is more likely to occur in companies with low transparency. Low transparency means that firm-specific information cannot be fairly and comprehensively received by investors. If managers try to hide bad news, stock price will reflect a positive deviation. When managers give up hoarding bad news, bad news would rush into the market intensively, leading to a stock price crash. This paper provides evidence on "bad news hoarding" theory from the perspective of internal control and systematically explains the mechanism of how internal control effectiveness restrains stock price crash risk. In the practical aspect, this paper illustrates that effective internal control can not only enhance transparency but also decrease stock price 
crash risk through improving transparency, highlighting the importance of internal control on mitigating information asymmetry between investors and managers.

\section{Acknowledgements}

This research was funded by National Natural Science Foundation of China (71672046 and 71532004).

\section{References}

[1] Jin, L. and S. C. Myers (2006). $\mathrm{R}^{2}$ around the world: New theory and new tests. Journal of Financial Economics, 79 (2), 257-292.

[2] Doyle, J. T., W. Ge, and S. McVay (2007). Accruals quality and internal control over financial reporting. The Accounting Review, 82 (5), 1141-1170.

[3] Chan, K. C., B. Farrell, and P. Lee (2008). Earnings management of firms reporting material internal control weaknesses under Section 404 of the Sarbanes-Oxley Act. Auditing: A Journal of Practice \& Theory, 27 (2), 161-179.

[4] Ashbaugh-Skaife, H., et al. (2008). The effect of SOX internal control deficiencies and their remediation on accrual quality. The Accounting Review. 83 (1), 217-250.

[5] Goh, B. W. and D. Li (2011). Internal controls and conditional conservatism. Accounting Review, 86 (3), 975-1005.

[6] Rice, S. C., D. P. Weber, and B. Wu (2015). Does SOX 404 have teeth? Consequences of the failure to report existing internal control weaknesses. Accounting Review, (3), 1169-1200.

[7] Feng, M., et al. (2015). Does ineffective internal control over financial reporting affect a firm's operations? Evidence from firms' inventory management. The Accounting Review, (2), 529-557.

[8] D'Mello, R., X. Gao, and Y. Jia (2017). Internal control and internal capital allocation: evidence from internal capital markets of multi-segment firms. Review of Accounting Studies, 22 (1), 251-287.

[9] Chen, C., J.-B. Kim, and L. Yao (2017). Earnings smoothing: Does it exacerbate or constrain stock price crash risk? Journal of Corporate Finance, 42, 36-54.

[10] Kubick, T. R. and G. B. Lockhart (2016). Proximity to the SEC and stock price crash risk. Financial Management, 45 (2), 115-127.

[11] Xu, N., et al. (2017). Analyst herding and stock price crash risk: Evidence from China. Journal of International Financial Management \& Accounting, 28 (3), 308-348.

[12] Liang, Q., D. Li, and W. Gao (2020). Ultimate ownership, crash risk, and split share structure reform in China. Journal of Banking and Finance, 113, 105751.

[13] Hutton, A. P., A. J. Marcus, and H. Tehranian (2009). Opaque financial reports, $\mathrm{R}^{2}$, and crash risk. Journal of Financial Economics, 94 (1), 67-86.

[14] Kothari, S. P., S. Shu, and P. D. Wysocki (2009). Do managers withhold bad news? Journal of Accounting Research, 47 (1), 241-276.

[15] Piotroski, J. D., T. J. Wong, and T. Zhang (2015). Political incentives to suppress negative information: Evidence from Chinese listed firms. Journal of Accounting Research, 53 (2), 405-459.

[16] Baron, R. M. and D. A. Kenny (1986). The moderator-mediator variable distinction in social psychological research: conceptual, strategic, and statistical considerations. Journal of Personality and Social Psychology, 51 (6), 1173-1182.

[17] Kim, J.-B., Y. Li, and L. Zhang (2011). CFOs versus CEOs: Equity incentives and crashes. Journal of Financial Economics, 101 (3), 713-730.

[18] Chen, J., H. Hong, and J. C. Stein (2001). Forecasting crashes: trading volume, past returns, and conditional skewness in stock prices. Journal of Financial Economics, 61 (3), 345-381. 